\title{
NHCs and Visible Light-mediated Photoredox Co-catalyzed Radical 1,2- Dicarbonylation of Alkenes for 1,4-Diketones
}

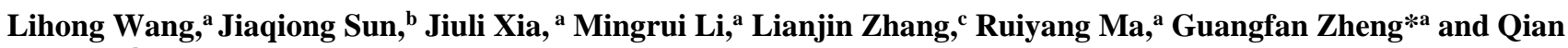 \\ Zhang*a,d \\ a. Jilin Province Key Laboratory of Organic Functional Molecular Design \& Synthesis, Department of ChemistryNortheast Normal \\ University, Changchun 130024, China E-mail: zhenggf265@nenu.edu.cn; zhangq651@nenu.edu.cn. \\ b. School of Environment, Northeast Normal University, Changchun 130117, China \\ c. Department of Chemistry, KAIST, 291 Daehak-ro, Yuseong-gu, Daejeon 34141, Korea \\ d. State Key Laboratory of Organometallic Chemistry, Shanghai Institute of Organic Chemistry, Chinese Academy of Sciences, 345 \\ Lingling Lu, Shanghai 200032, China
}

\begin{abstract}
Alkenes are ubiquitous, and radical difunctionalization of alkenes represents one of the most practical approaches to constructing value-added compounds. Dicarbonylation of alkenes provides direct access to value-added 1,4-dicarbonyl compounds. However, selectivity control for unsymmetric 1,2-dicarbonylation is an unclosed challenge. We herein describe NHCs and photocatalysis co-catalyzed three competent radical 1,2-dicarbonylation of alkenes by distinguishing two carbonyl groups, providing structurally diversified 1,4-diketones. Mechanistic studies indicated that NHCs-stabilized ketyl-type radicals originate from aroyl fluorides via oxidative quenching process of excited photocatalysis, and acyl radicals are generated from single-electron-oxidation of $\alpha$-keto acids. Distinct properties of acyl radical and NHCs-stabilized ketyl radical contributed to selectivity control. Transient acyl radicals are rapidly added to alkenes delivering alkyl radicals, which undergo subsequent radical-radical cross-coupling with ketyl-type radicals, affording 1,2-dicarbonylation products. This transformation features mild reaction conditions, broad substruct scope, and excellent selectivity, providing a general and practical approach for the dicarbonylation of olefins.
\end{abstract}

\section{Introduction}

Alkenes are ubiquitous and fundamental motifs in organic molecules. Radical difunctionalization of alkenes ${ }^{1}$ is one of the most practical approaches to constructing value-added compounds in the atom- and stepeconomic manner and with significant synthetic potential. Since the radical-radical cross-couplings preceded nearly diffusion-controlled processes, ${ }^{2}$ steric hindrance and electron effects were insensitive, representing an attractive approach for the difunctionalization of $\mathrm{C}=\mathrm{C}$ bonds. However, selectivity control for radical-radical cross-coupling pathways was a formidable challenge. The research was limited to two radicals with apparent differences in properties, such as transient radicals and persistent radicals..$^{2-3}$ Reactivity is the natural property of the radical species depending on the structure; distinguishing the reactivity for two radicals with a similar structure is a significantly attractive but challenging task in radical chemistry. Turning the radical reactivity ${ }^{4}$ might be essential to achieve selectivity control.

1,4-Dicarbonyl compounds found widespread applications in pharmaceutical molecules, bioactive natural compounds, and materials science. ${ }^{5}$ Direct dicarbonylation of alkenes might provide straightforward access to 1,4-Dicarbonyl compounds. ${ }^{6-10}$ Symmetric 1,2-dicarbonylations have been achieved by employing a stoichiometric reducing agent, ${ }^{6}$ or NHCs-catalyzed Stetter reaction for activated Michael acceptor (Scheme 1b). ${ }^{7}$ Recently, Xia et al. developed symmetric 1,2-dicarbonylations of olefins, in which the second C-acyl bond was formed via Ni-participated reductive eliminations. ${ }^{8}$ For unsymmetric 1,2 -dicarbonylation, selectivity is an unclosed problem (Scheme $1 \mathrm{~b}$ ). ${ }^{7 \mathrm{a}} \mathrm{Wu}$ and co-works achieved the major breakthrough in this domain by employing a visible light-mediated radical-polar cross-coupling strategy (Scheme 1c). ${ }^{9}$ Efficient distinguishment of amide acyl and arylformyl groups was developed for the first time by tuning the reductive and electrophilic ability of acyl precursors. Despite the significance, the development of general unsymmetric 1,2-dicarbonylation of olefins, especially for the selective installation of two similar acyl groups, was highly attractive and largely underdeveloped. ${ }^{9-10}$

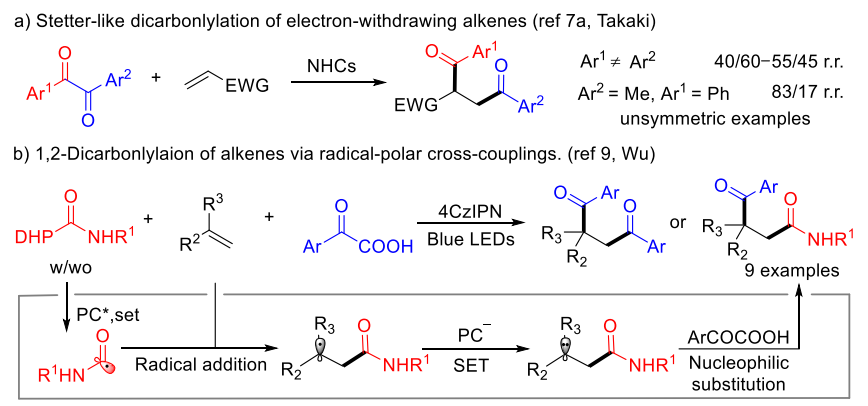

c) This work: Selecitive radical 1,2-dicarbonylation of alkenes via radical-radical cross-couplings.

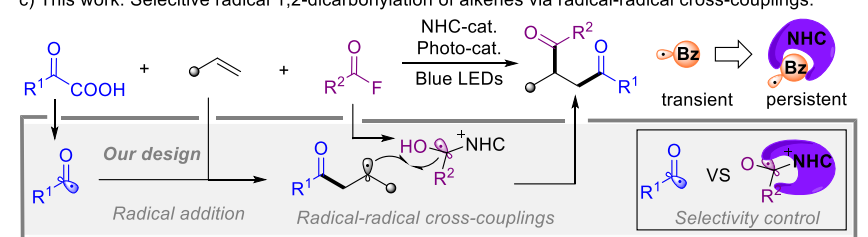

Scheme 1 Unsymmetric 1,2-dicarbonylation of Alkenes 
As distinctive radical species, acyl radicals play an essential role in the construction of carbonyl compounds. Most frequently, acyl radicals undergo addition to unsaturated bonds. ${ }^{11}$ NHCs inhibit predominant activity $^{12}$ in constructing the carbon-acyl bond via the polar pathway. Recently, NHCs-catalyzed radical transformation opened a new avenue for radical acylation chemistry that enables NHCs-stabilized ketyl-type radicals $^{13}$ to undergo radical-radical cross-coupling. ${ }^{14}$ Pioneered by Omiya et al., ${ }^{15 a}$ numerous elegant progress has been developed for direct coupling ${ }^{15,16,20 \mathrm{a}-\mathrm{c}}$ or difunctionalization strategy, ${ }^{17-19,20 \mathrm{~d}-\mathrm{f}}$ providing alternative methods for synthesizing functionalized ketone units. ${ }^{14-20}$ Cooperation of NHCs with photocatalysis is attractive that realizes novel transformation under very mild reaction conditions. ${ }^{16,18,20,21}$ In this domain, Studer, ${ }^{20 c-f}$ Scheidt, ${ }^{16 a-c, 18 b}$ and $\mathrm{Chi}^{16 \mathrm{~d}}$ et al. made significant contributions for the radical transformation of acylazolium intermediate. Studer et al. developed new properties of aroyl fluorides, ${ }^{20 c-f}$ which could act as efficient ketyl-type radical precursors via photo-induced single-electron transfer. Motivated by that elegant progress ${ }^{20 \mathrm{c}-\mathrm{f}}$ and acyl radical formation from $\alpha$-keto acids, ${ }^{22}$ we envisaged that cooperation of NHCs and photocatalysis ${ }^{16,18,20,21}$ enables the generation of acyl radicals and NHCsstabilized ketyl radicals under extremely mild conditions, which may provide a solution for challenging distinguishment for similar acyl radicals (Scheme 1c). As our longstanding interests in radical chemistry, ${ }^{23}$ we now describe our findings in three-component unsymmetric radical 1,2-dicarbonylation of alkenes by turning reactivity of one acyl radicals, providing direct access to structurally diversified 1,4-diketones (Scheme 1c).

\section{Results and discussion}

Table 1 Condition optimizations. ${ }^{a, b}$

\begin{tabular}{|c|c|c|c|c|c|}
\hline \multirow{2}{*}{$\begin{array}{c}\text { 1a } \\
\text { Entry }\end{array}$} & \multirow{2}{*}{$\begin{array}{c}{ }_{2 a}^{+}{ }_{\text {Nh }}^{\mathrm{O}_{F}} \\
\text { NHC Cat. } \\
(15 \mathrm{~mol} \%)\end{array}$} & \multirow{2}{*}{$\begin{array}{l}\text { 3a } \\
\mathrm{PC}(1.5 \\
\mathrm{mol} \%) \\
\end{array}$} & \multicolumn{2}{|c|}{$\begin{array}{c}\text { PC }(1.5 \mathrm{~mol} \%) \\
\text { NHCs (15 mol\%) } \\
\text { Base }(2.0 \text { equiv) } \\
\text { Blue LED } \\
\text { Solvent, rt, } 24 \mathrm{~h}\end{array}$} & \multirow{2}{*}{$\begin{array}{c}4 \\
\text { Yields } \\
(\%)\end{array}$} \\
\hline & & & $\begin{array}{l}\text { Solvent } \\
(2 \mathrm{~mL})\end{array}$ & $\begin{array}{c}\text { Base } \\
\text { (2.0 eq.) }\end{array}$ & \\
\hline 1 & NHC-1 & PC-1 & DCM & $\mathrm{Cs}_{2} \mathrm{CO}_{3}$ & 34 \\
\hline 2 & NHC-1 & PC-1 & DCM & $\mathrm{K}_{2} \mathrm{PO}_{4}$ & 20 \\
\hline 3 & NHC-1 & PC-1 & DCM & DBU & 28 \\
\hline 4 & NHC-1 & PC-1 & Dioxane & $\mathrm{Cs}_{2} \mathrm{CO}_{3}$ & 44 \\
\hline 5 & NHC-1 & PC-1 & THF & $\mathrm{Cs}_{2} \mathrm{CO}_{3}$ & 45 \\
\hline 6 & NHC-1 & PC-1 & ${ }^{t} \mathrm{BuOMe}$ & $\mathrm{Cs}_{2} \mathrm{CO}_{3}$ & 42 \\
\hline 7 & NHC-1 & PC-1 & $\mathrm{CH}_{3} \mathrm{CN}$ & $\mathrm{Cs}_{2} \mathrm{CO}_{3}$ & 28 \\
\hline 8 & NHC-1 & PC-1 & Tolune & $\mathrm{Cs}_{2} \mathrm{CO}_{3}$ & 74 \\
\hline 9 & NHC-2 & PC-1 & Tolune & $\mathrm{Cs}_{2} \mathrm{CO}_{3}$ & 56 \\
\hline 10 & NHC-3 & PC-1 & Tolune & $\mathrm{Cs}_{2} \mathrm{CO}_{3}$ & trace \\
\hline 11 & NHC-4 & PC-1 & Tolune & $\mathrm{Cs}_{2} \mathrm{CO}_{3}$ & 12 \\
\hline 12 & NHC-5 & PC-1 & Tolune & $\mathrm{Cs}_{2} \mathrm{CO}_{3}$ & 62 \\
\hline 13 & NHC-1 & PC-2 & Tolune & $\mathrm{Cs}_{2} \mathrm{CO}_{3}$ & 69 \\
\hline 14 & NHC-1 & PC-3 & Tolune & $\mathrm{Cs}_{2} \mathrm{CO}_{3}$ & n.d. \\
\hline 15 & NHC-1 & PC-4 & Tolune & $\mathrm{Cs}_{2} \mathrm{CO}_{3}$ & 40 \\
\hline 16 & NHC-1 & PC-5 & Tolune & $\mathrm{Cs}_{2} \mathrm{CO}_{3}$ & n.d. \\
\hline $17^{c}$ & NHC-1 & PC-1 & Tolune & $\mathrm{Cs}_{2} \mathrm{CO}_{3}$ & 72 \\
\hline
\end{tabular}

PC-1: [Ir(ppy $)_{2}($ dtbbpy $\left.)\right] \mathrm{PF}_{6}$ PC-3: $\operatorname{Ir}(\mathrm{ppy})_{3}$
PC-2: $\left[\mathrm{Ir}\left[\mathrm{dF}\left(\mathrm{CF}_{3}\right) \mathrm{ppy}\right]_{2}(\mathrm{dtbbpy})\right] \mathrm{PF} \mathrm{F}_{6}$

$$
\text { PC-4: 4CZIPN PC-5: Ru(bpy })_{3}\left(\mathrm{BF}_{4}\right)_{2}
$$

${ }^{a}$ Unless otherwise noted, all the reactions were carried out with 1a $(0.1$ $\mathrm{mmol}), 2 \mathbf{a}(0.2 \mathrm{mmol}), 3 \mathbf{a}(0.2 \mathrm{mmol}), \mathbf{N H C s}(0.015 \mathrm{mmol}), \mathrm{Cs}_{2} \mathrm{CO}_{3}(0.2$ $\mathrm{mmol})$, and PC (0.0015 mmol) in anhydrous solvent, irradiation with Blue LEDs at room temperature for $4 \mathrm{~h} .{ }^{b}$ isolated yields. ${ }^{c} 0.2 \mathrm{mmol}$ scale reaction was conducted.

Our initial study of the 1,2-dicarbonylation of alkenes commenced with the dicarbonylation of styrene (1a) with benzoyl fluoride (2a) and benzoic acid (3a). Fortunately, by employing NHC-1 (15 mol\%) and $\left[\operatorname{Ir}(\mathrm{ppy})_{2}(\mathrm{dtbbpy})\right] \mathrm{PF}_{6}(1.5 \mathrm{~mol} \%)$ as catalyst, $\mathrm{Cs}_{2} \mathrm{CO}_{3}(2.0$ equiv) as base under Blue LED irradiation in DCM afforded desired 1,4-diketone 4 in $34 \%$ yields (Table1, entry 1 ). Other bases, such as $\mathrm{K}_{2} \mathrm{PO}_{4}$ and DBU, were also effective with slightly lower yields. Dioxane, THF, ${ }^{t} \mathrm{BuOMe}$, and $\mathrm{CH}_{3} \mathrm{CN}$ could promote the transformation effectively with moderate yields (entries 4-7). The yields could improve to 74\% when switching the solvent to PhMe (entry 8). An NHCs screen indicated that NHC-1 is the most effective catalyst compared with other NHCs (entries 8-12); steric hindrance NHCs seem to be more suitable for this cascade reaction. Replacing the photocatalysts to $\operatorname{Ir}\left[\mathrm{dF}\left(\mathrm{CF}_{3}\right) \mathrm{ppy}_{2}\right.$ (dtbpy)]PF6 and 4CZIPN provided 4 in 69 and $40 \%$ yields. However, no product was observed for PC-4 and PC-5. When the reaction was carried out at $0.2 \mathrm{mmol}$ scales, the desired 1,4-diketone $\mathbf{4}$ could be separated in $72 \%$ yield.

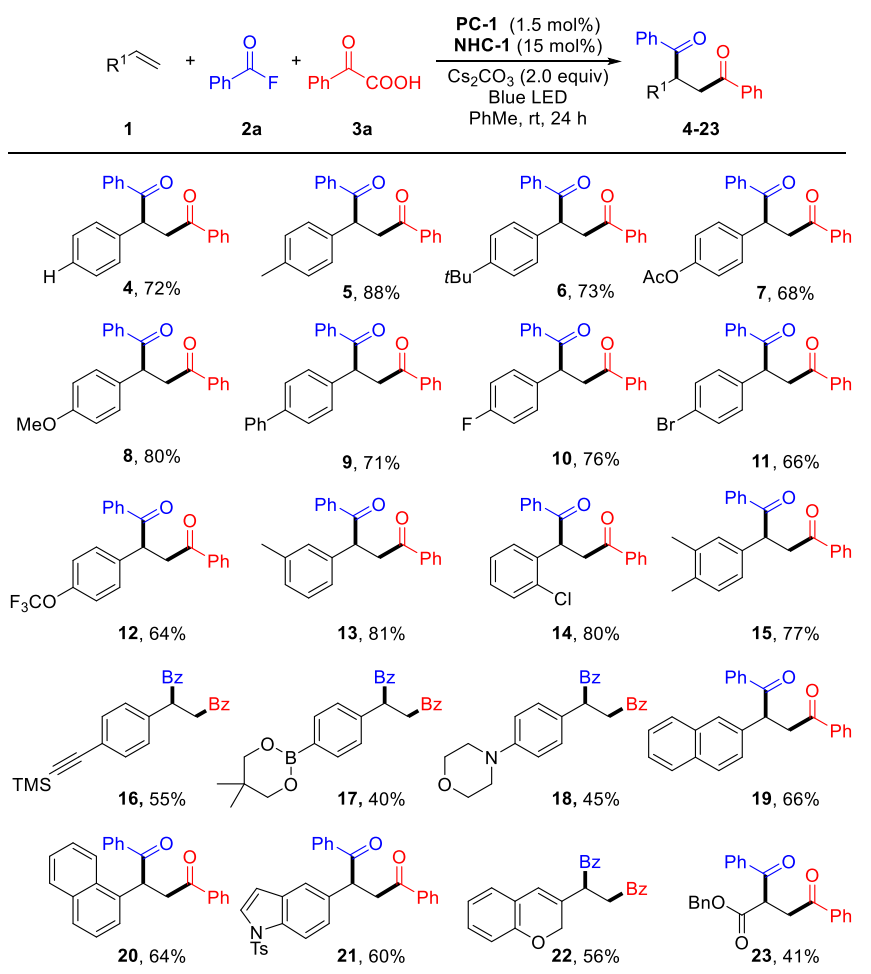

Scheme 2 Substrate scope for symmetric 1,2-dicarbonylation of Alkenes. ${ }^{a, b}$ Conditions A: Unless otherwise noted, all the reactions were carried out with $1(0.2 \mathrm{mmol}), \mathbf{2 a}(0.4 \mathrm{mmol}), 3 \mathbf{3 a}(0.4 \mathrm{mmol})$, NHC-1 (0.03 mmol), PC-1 (0.003 mmol) and $\mathrm{Cs}_{2} \mathrm{CO}_{3}(0.4 \mathrm{mmol})$ in PhMe (4 mL) at $\mathrm{rt}$ under $\mathrm{N}_{2}$, irradiation with Blue LED (453.5 nm, $5 \mathrm{~W}$ ) for $24 \mathrm{~h} .{ }^{b}$ Isolated yield.

With the optimized conditions in hand, we next explored the substruct scope for this 1,2-dicarbonylation. As shown in Scheme 2, styrene derivatives bearing electron-donating (methyl, $t$-butyl, methoxycarbonyl, methoxyl), phenyl, halogen (fluorine, bromine), or strong electronwithdrawing trifluoromethoxy group at the para position were all well tolerated and affording 1,4-diketone 4-12 in 66-80\% yields, indicating the intensity of electron effect. This transformation shows well tolerances to steric hindrance as identified by meta- $(\mathbf{1 3}, 81 \%)$, or orth-(14, 82\%) substituted styrenes. Disubstituted styrenes were also applicable for this 




Scheme 3 Substrate scope for symmetric 1,2-dicarbonylation of Alkenes. ${ }^{a}$ Conditions B: For aryl-substituted $\alpha$-keto acids, the reactions were carried out with $1(0.2 \mathrm{mmol}), \mathbf{2}(0.6 \mathrm{mmol}), \mathbf{3}(0.6 \mathrm{mmol})$, NHC-1 $(0.03 \mathrm{mmol})$, PC-1 $(0.003 \mathrm{mmol})$ and $\mathrm{Cs}_{2} \mathrm{CO}_{3}(0.4 \mathrm{mmol})$ in PhMe $(4 \mathrm{~mL})$ at $\mathrm{rt}$ under $\mathrm{N}_{2}$, irradiation with Blue LED ( $453.5 \mathrm{~nm}, 5 \mathrm{~W}$ ) for $24 \mathrm{~h}$. isolated yields. Conditions C: For alkyl-substituted $\alpha$-keto acids, DCM was employed as the solvent instead of PhMe. Isolated yields. ${ }^{b} \mathbf{2}(0.8 \mathrm{mmol}), \mathbf{3}(0.8 \mathrm{mmol})$ was employed. 
dicarbonylation. Furthermore, vulnerable trimethylsilyl ethynyl (16), boric ester (17) and morpholino (18) groups were left intact under reaction conditions, providing an opportunity for further transformation. Naphthalene (19, 20), indole (21), 2H-chromene (22) substituted styrenes could also deliver the desired product in $56-66 \%$ yields. This $1,2-$ dicarbonylation system could be extended to Michael acceptor (23).

After defining the scope of symmetric 1,2-dicarbonylation, we turned attention to the more challenging unsymmetric 1,2-dicarbonylations, which could reflect the advantages of designed tricomponent cascade reaction. First, we attempted the scope of acyl radical source, and the results were summarized in Scheme 3a. Different benzoylformic acids bearing a range of functional groups were well tolerated, including alkyl $(\mathbf{2 4}, \mathbf{2 5})$, strong electron-donating methoxyl (26), halogen (27), and strong electron-withdrawing trifluoromethoxy (28) group. Meta- (30), orth- (29), and sterically encumbered 2,4,6-tri- (31) substituted benzoylformic acids were competent to afford the products in acceptable yield. Thiophene substituted benzoylformic acid was proved to be an efficient acylation source and provided 32 in $65 \%$ yield. It should be noted that our 1,2dicarbonylation system could be further extended to pyruvic acid and its derivatives, affording 33-35 in $52-72 \%$ yield with slightly modified conditions. To the best of our knowledge, this is the first practical selective acetylative carbonylation. We next explore the scope of aroyl fluorides by employing pyruvic acid as an acetylation source (Scheme 3b). To our delight, this acetylative carbonylation strategy was tolerated with various electron-donating (alkyl, methoxyl), halogen (fluorine, chlorine, bromine), electron-withdrawing (ester carbonyl), and phenyl substituents at para (36-43), meta (44), or ortho (45) positions of the phenyl rings, affording 36-45 in 40-80\% yields. Electron-withdrawing aroyl fluoride exhibited slightly lower activity $(\mathbf{4 3}, 40 \%)$. 2,4-diMe-substituted aroyl fluoride (45, $52 \%$ ) was proved to be an effective ketyl-type radical precursor the acetylative carbonylation. Naphthyl fluoride was also tolerated in this cascade reaction, delivering 47 in $47 \%$ yield. While this method demonstrates the considerable scope for benzoylformic acids and aroyl fluorides, we next investigate the substruct scope of olefins for unsymmetric 1,2-dicarbonylations. As summarized in Scheme 3c, various styrenes and Michael acceptors were tolerated and afforded 48-76 in moderate to high yields. For styrenes, the electron-donating group at the para position of phenyl rings provides excellent reactivity, providing 4854 65-84\% yields. Acetoxy (50, 73\%), benzyl chloride (54, 68\%), and methylthio $(\mathbf{5 3}, \mathbf{7 0} \%)$ groups were tolerated, indicating broad application scope. Halogen (fluorine, chlorine, bromine) groups were applicable (5557), which might provide the opportunity for cross-coupling. Methoxycarbonyl substituted aryl olefin could converted to $\mathbf{5 8}$ in $\mathbf{7 0 \%}$ yield. Strong electron-withdrawing trifluoromethoxy and trifluoromethyl groups were also compatible with this cascade reaction, and corresponding product $\mathbf{5 9}$ and $\mathbf{6 0}$ was isolated in $\mathbf{5 6}$ and $62 \%$ yield, respectively. 2-Me $(\mathbf{6 3}, 71 \%), 3,4-d i \mathrm{Me}(\mathbf{6 4}, 67 \%)$ and 2,3-diOMe $(\mathbf{6 5}$, $60 \%$ ) substituted aryl olefins were also effective. Furthermore, some potentially reactive functional groups, such as Bpin $(\mathbf{6 6}, 66 \%)$, insular alkyne $(\mathbf{6 7}, 54 \%)$, and olefin $(\mathbf{6 8}, 42 \%)$ units have been preserved in our system. Notably, heterocycle substrates were suitable for this chemistry, such as pyridine $(69,54 \%)$. This strategy was also applicable for acetylation carbonylation of acrylate, affording $\mathbf{7 0}$ and $\mathbf{7 1}$ in 54 and 60\% yield, respectively. Finally, we also tested the substrate scope of unsymmetric 1,2-dicarbonylations by installing benzoyl and 4chlorobenzoyl groups. Preliminary attempts show electron-donating (7274) and -withdrawing group (75) substituted phenyl ring, and naphthalene ring (76) were competent, delivering 1,4-diketone in 50-66\% yields. The scope and selectivity of this NHCs and PC co-catalyzed system are quite broad and practical, addressing the important unsolved problem of classical methods for 1,2-dicarbonylation of olefins.
To get further information for 1,2-dicarbonylation, we performed a series of mechanism investigations (Scheme 4). Control experiments indicate NHCs, photocatalysis, and visible lights were indispensable for 1,2-dicarbonylation of olefins (Scheme 4a). The yield of $\mathbf{3 6}$ was dropped to $20 \%$ when the radical scavenger 2,2,6,6tetramethylpiperidine 1-oxyl (TEMPO) was added, and TEMPOtrapping product 77 was isolated in $55 \%$ yield (Scheme $4 \mathrm{~b}$ ). This result indicates that the reaction might be procced via a radical mechanism involving ketyl radical originating from aroyl fluorides. We synthesized acyl azolium ion $\mathbf{7 8}$ and applied it in the dicarbonylation reaction without NHCs. Desired product $\mathbf{3 6}$ was isolated in $32 \%$ yields (Scheme 4c), supporting acyl azolium ion might be the efficient intermediate. Furthermore, when employing 3,3-dimethyl-2-oxobutanoic acid $\mathbf{3 n}$ as a radical precursor, alkylative acylation product $\mathbf{7 9}$ was identified, which might proceed via decarbonylation of $t$-Bu carbonyl radical species (Scheme 4d). Stern-Volmer quenching studies indicate the excited state of $\left[\operatorname{Ir}(\mathrm{ppy})_{2}(\mathrm{dtbbpy})\right] \mathrm{PF}_{6}$ was preferred to quenched by acyl azolium ion 78, instead of pyruvic acid or olefins (Figure S1-4), which has a significant difference with $\mathrm{Wu}^{9} \mathrm{~s}^{9}$ system. This result indicates the oxidative quenching process of the photocatalyst.

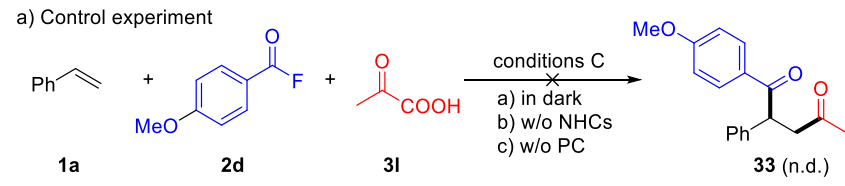

b) Radical inhibiter experiment

$$
\mathbf{1 b}+\mathbf{2 a}+31 \frac{\text { conditions } \mathrm{C}}{\operatorname{TEMPO}(4.0 \text { equiv })} \mathbf{3 6}(<5 \%)+
$$

c) Possible intermediate

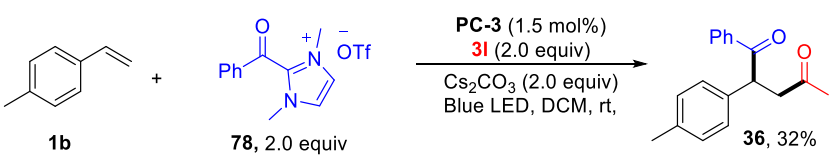

d) Formation of acyl radical intermediate

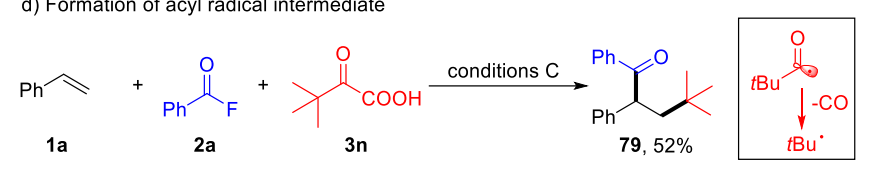

Scheme 4 Mechanism investigation

Based on a series of experimental studies and insights from previous reports, we propose a mechanistic picture for the 1,2dicarbonylation in Scheme 5. Acylazolium intermediate $\mathbf{I}$ is generated from the reaction of the aroyl fluoride, or its analogs $\mathbf{A}$ react with NHCs. In situ generated excited state of $\left[\operatorname{Ir}(\mathrm{ppy})_{2}(\mathrm{dtbbpy}) \mathrm{PF}_{6}\right.$ undergo oxidative quenching by Acylazolium intermediate $\mathbf{I}$ afford the $\mathrm{Ir}^{\mathrm{IV}}$-complex, and NHCs stabilized persistent ketyl-type radical species $\mathbf{I I}$. Ir ${ }^{\mathrm{IV}}$-complex could oxidate pyruvic acid $\mathbf{B}$ to yield transient acyl radical III and regenerate the ground-state photocatalyst for the next photocatalyst cycle. Distinct properties of acyl and NHCs-stabilized ketyl radical Show different reactivity regard with olefins. Transient acyl radical III undergoes radical addition to the double bond of olefin $\mathbf{C}$ delivering alkyl radical IV, which is specifically trapped by persistent ketyl-type radical II providing NHCs-linked intermediate V. Persistent radical effect $^{2 \mathrm{~d}}$ made critical contributions to selectivity control towards acyl and ketyl-type radical in radical-radical coupling strategy. 
Dissociation of NHCs from VI affording the 1,4-diketone D, completes the NHCs catalytic cycle. Additionally, the above evidence for free radical intermediates originated from aroyl fluoride (Scheme 4b) and pyruvic acid (Scheme 4d), and photochemical experiments are consistent with this catalytic cycle.

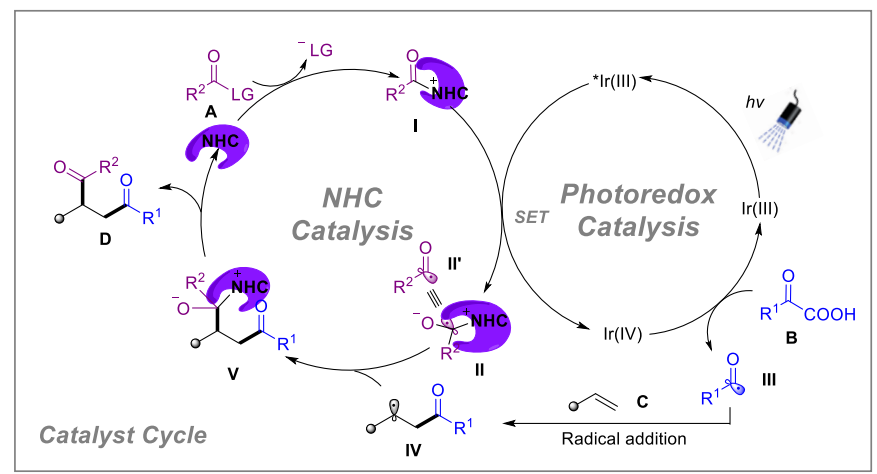

Scheme 5 Proposed catalytic cycle

\section{Conclusions}

In summary, we have developed an efficient NHCs Photoredox Cocatalyzed three-component unsymmetric radical 1,2-dicarbonylation of alkenes by turning reactivity of one acyl radicals. Mechanistic studies indicated that the reaction proceeded via radical-radical cross-couplings. Ketyl radicals originate from aroyl fluorides via the oxidative quenching process of excited photocatalysis, while the acyl radicals are formed from single-electron-oxidation of $\alpha$-keto acids. Distinct properties of acyl radical and NHCs-stabilized ketyl radical contributed to selectivity control. Different from Wu's strategy, ${ }^{9}$ we realized selective 1,2-dicarbonylation for two aroyl groups or aroyl and alkanoyl groups. To the best of our knowledge, this strategy represents the first selective three-component dicarbonylation of olefins installing aroyl and alkanoyl groups. ${ }^{9,10}$ The transformation proceeds under extremely mild conditions with good functional group tolerance and broad scope (73 examples, up to $84 \%$ yield), providing a general and practical approach for unsymmetric 1,2dicarbonylation of olefins.

\section{Data availability}

Data for all compounds in this manuscript are available in the ESI, $\dagger$ which includes experimental details, characterization and copies of ${ }^{1} \mathrm{H}$ and ${ }^{13} \mathrm{C}$ NMR spectra.

\section{Author Contributions}

L. W., J. S., J. X., R. M., and M. L. performed the experiments and analyzed data. L. Z. participated in writing the paper. G. Z., and Q. Z. conceived the concept, directed the project and wrote the paper.

\section{Conflicts of interest}

There are no con conflicts to declare.

\section{Acknowledgements}

We acknowledge the NSFC (22001157,21831002, and 22193012), Ten Thousand Talents Program, the Fundamental Research Funds for the Central Universities (2412021QD007), and the Natural Science Foundation of Shaanxi Province (2020JQ-404) for generous financial support.

\section{Notes and references}

1 (a) E. Merino and C. Nevado, Chem. Soc. Rev., 2014, 43, 6598-6608; (b) M. Yan, J. C. Lo, J. T. Edwards and P. S. Baran, J. Am. Chem. Soc., 2016, 138, 12692-12714; (c) X. Wu, S. Wu and C. Zhu, Tetrahedron Lett., 2018, 59, 1328-1336; (d) G. S. Sauer and S. Lin, ACS Catal., 2018, 8, 5175-5187; (e) F. Wang, P. Chen and G. Liu, Acc. Chem. Res., 2018, 51, 2036-2046; (f) T. Koike and M. Akita, Chem, 2018, 4, 409437; (g) L. Pitzer, J. L. Schwarz, F. Glorius, Chem. Sci., 2019, 10, 8285-8291; (h) Z. Li, G. Fang, Q. Gu and X. Liu, Chem. Soc. Rev., 2020,49, 32-48; (i) X. Wu, C. Zhu, Acc. Chem. Res., 2020, 53, 1620 1636; (j) H. Jiang, A. Studer, Chem. Soc. Rev., 2020, 49, 1790-1811; (k) S. Sharma, J. Singh and A. Sharmaa, Adv. Synth.Catal., 2021, 363, 3146-3169.

2 (a) H. Fischer, Chem. Rev., 2001, 101, 3581-3610; (b) K. J. Romero, M. S. Galliher, D. A. Pratt, C. R. J. Stephenson, Chem. Soc. Rev., 2018, 47, 7851-7866; (c) J. Luo and W. Wei, Adv. Synth. Catal., 2018, 360, 2076-2086. (d) D. Leifert, A. Studer, Angew. Chem., Int. Ed., 2020, 59, 74-108;

3 (a) A. McNally, C. K. Prier, D. W. C. MacMillan, Science, 2011, 334, 1114-1117; (b) M. Hartmann, Y. Li and A. Studer, J. Am. Chem. Soc., 2012, 134, 16516-16519; (c) Y. Li and A. Studer, Angew. Chem., Int. Ed., 2012, 51, 8221-8224; (d) E. Speckmeier, T. G. Fischer, K. Zeitler, J. Am. Chem. Soc., 2018, 140, 15353-15365; (e) H. A. Beejapur, Q. Zhang, K. Hu, L. Zhu, J. Wang and Z. Ye, ACS Catal., 2019, 9, 2777-2830; (f) S. Zhu, J. Qin, F. Wang, H. Li, L. Chu, Nat. Commun., 2019, 10, 749-756; (g) T. Patra, M. Das, C. G. Daniliuc and F. Glorius, Nature Catal., 2021, 4, 54-61; (h) S. Lai, B. Wei, J. Wang, W. Yu and B. Han, Angew. Chem. Int. Ed., 2021, 60, 21997-22003; (i) C. Xu, J. Li, J. Xiang and W. Deng, Org. Lett., 2021, 23, 3696-3700;

4 (a) S. Wang, S. Tang and A. Lei, Science Bulletin, 2018, 63, 10061009; (b) B. Tang, J. Zhao, J. Xu and X. Zhang, Chem. Sci., 2020, 11, 1192-1204.

5 (a) A. Furstner, T. Nagano, J. Am. Chem. Soc., 2007, 129, 1906-1907; (b) H. Renata, Q. H. Zhou, G. Dunstl, J. Felding, R. R. Merchant, C. H. Yeh, P. S. Baran, J. Am. Chem. Soc., 2015, 137, 1330-1340; (c) J. T. Edwards, R. R. Merchant, K. S. McClymont, K. W. Knouse, T. Qin, L. R. Malins, B. Vokits, S. A. Shaw, D.-H. Bao, F.-L. Wei, T. Zhou, M. D. Eastgate, P. S. Baran, Nature, 2017, 545, 213-219; (d) R. L. Sutar, S. Sen, O. Eivgi, G. Segalovich, I. Schapiro, O. Reany, N. G. Lemcoff, Chem. Sci., 2018, 9, 1368-1374.

6 (a) N.-S. Li, S. Yu, G. W. Kabalka, Organometallics, 1998, 17, 38153817; (b) Y. Yamamoto, H. Maekawa, S. Goda, I. Nishiguchi, Org. Lett., 2003, 5, 2755-2758; (c) Y. Liu, Y. Zhang, Tetrahedron, 2003, 59, 8429-8437.

7 (a) K. Takaki, A. Ohno, M. Hino, T. Shitaoka, K. Komeyama, H. Yoshida, Chem. Commun., 2014, 50, 12285-12288; (b) K. Takaki, M. Hino, A. Ohno, K. Komeyama, H. Yoshida, H. Fukuoka, Beilstein J. Org. Chem., 2017, 13, 1816-1822.

8 X. Zhao, B. Li, W. Xia, Org. Lett., 2020, 22, 1056-1061.

9 Y. Cheng, J. Yu, T. Lei, H. Hou, B. Chen, C. Tung and L. Wu, Angew. Chem. Int. Ed., 2021, 60, 26822-26828.

10 S. Jin, X. Sui, G. C. Haug, V. D. Nguyen, H. T. Dang, H. D. Arman, and O. V. Larionov, ACS Catal., 2022, 12, 285-294 (during our preparation, Larionov et al. developed 1,2-diacylation of alkenes; however, subtract scope was limited to installation of two aryl acyl groups).

11 (a) C. Chatgilialoglu, D. Crich, M. Komatsu and I. Ryu, Chem. Rev., 1999, 99, 1991-2069; (b) A. Banerjee, Z. Lei and M. Ngai, Synthesis, 
2019, 303-333; (c) Y. Liu, Y. Ouyang, H. Zheng, H. Liu and W. Wei, Chem. Commun., 2021, 57, 6111-6120.

12 (a) D. Enders, O. Niemeier, A. Henseler, Chem. Rev., 2008, 107, 56065655; (b) X. Bugaut, F. Glorius, Chem. Soc. Rev., 2012, 41, 3511-3522; (c) M. N. Hopkinson, C. Richter, M. Schedler, F. Glorius, Nature, 2014, 510, 485-496; (d) R. S. Menon, A. T. Biju, V. Nair, Chem. Soc. Rev., 2015, 44, 5040-5052; (e) D. M. Flanigan, F. Romanov-Michailidis, N. A. White, T. Rovis, Chem. Rev., 2015, 115, 9307-9387; (f) K. J. R. Murauski, A. A. Jaworski, K. A. Scheidt, Chem. Soc. Rev., 2018, 47, 1773-1782; (g) X. Chen, Z. Gao, S. Ye, Acc. Chem. Res., 2020, 53, 690-702.

13 (a) I. Nakanishi, S. Itoh, T. Suenobu, S. Fukuzumi, Chem. Commun., 1997, 1997, 1927-1928; (b) J. K. Mahoney, D. Martin, C. E. Moore, A. L. Rheingold, G. Bertrand, J. Am. Chem. Soc., 2013, 135, 18766 18769; (c) V. Regnier, E. A. Romero, F. Molton, R. Jazzar, G. Bertrand, D. Martin, J. Am. Chem. Soc., 2019, 141, 1109-1117.

14 (a) K. Zhao and D. Enders, Angew. Chem. Int. Ed., 2017, 56, 37543756; (b) R. Song and Y. R. Chi, Angew. Chem. Int. Ed., 2019, 58, 8628-8630; (c) T. Ishii, K. Nagao and H. Ohmiya, Chem. Sci., 2020, 11, 5630-5636; (d) Q. Liu and X.-Y. Chen, Org. Chem. Front., 2020, 7, 2082-2087; (e) H. Ohmiya, ACS Catal., 2020, 10, 6862-6869; (f) K.-Q. Chen, H. Sheng, Q. Liu, P.-L. Shao and X.-Y. Chen, Sci. China Chem., 2021, 64, 7-16; (g) Q.-Z. Li, R. Zeng, B. Han and J.-L. Li, Chem. Eur. J., 2021, 27, 3238-3250; (h) Y. Sumoda and H. Ohmiya, Chem. Soc. Rev., 2021, 50, 6320-6332.

15 (a) T. Ishii, Y. Kakeno, K. Nagao and H. Ohmiya, J. Am. Chem. Soc., 2019, 141, 3854-3858; (b) Y. Kakeno; M. Kusakabe; K. Nagao and H. Ohmiya, ACS Catal., 2020, 10, 8524-8529; (c) I. Kim, H. Im, H. Lee and S. Hong, Chem. Sci., 2020, 11, 3192-3197.

16 (a) A. V. Davies, K. P. Fitzpatrick, R. C. Betori and K. A. Scheidt, Angew. Chem. Int. Ed., 2020, 59, 9143-9148; (b) A. A. Bayly, B. R McDonald, M. Mrksich and K. A. Scheidt, Proc. Natl. Acad. Sci. U. S. A., 2020, 117, 13261-13266; (c) A. V. Bay, K. P. Fitzpatrick, G. A González-Montiel, A. O. Farah, P. H. Cheong and K. A. Scheidt, Angew. Chem. Int. Ed., 2021, 60, 17925-17931; (d) S.-C. Ren, W.-X Lv, X. Yang, J.-L. Yan, J. Xu, F.-X. Wang, L. Hao, H. Chai, Z. Jin and Y. R. Chi, ACS Catal., 2021, 11, 2925-2934.

17 (a) T. Ishii, K. Ota, K. Nagao and H. Ohmiya, J. Am. Chem. Soc., 2019, 141, 14073-14077; (b) J.-L. Li, Y.-Q. Liu, W.-L. Zou, R. Zeng, X Zhang, Y. Liu, B. Han, Y. He, H.-J. Leng and Q.-Z. Li, Angew. Chem. Int. Ed., 2020, 59, 1863-1870; (c) K. Ota, K. Nagao and H. Ohmiya Org. Lett., 2020, 22, 3922-3925; (d) H.-B. Yang, Z.-H. Wang, J.-M. Li and C. Wu, Chem. Commun., 2020, 56, 3801-3804; (e) B. Zhang Q. Peng, D. Guo and J. Wang, Org. Lett., 2020, 22, 443-447; (f) Y. Matsuki, N. Ohnishi, Y. Kakeno, S. Takemoto, T. Ishii, K. Nagao and H. Ohmiya, Nat. Commun., 2021, 12, 3848.

18 (a) Y. Sato, Y. Goto, K. Nakamura, Y. Miyamoto, Y. Sumida and H. Ohmiya, ACS Catal., 2021, 11, 12886-12892; (b) P, Wang, K. P. Fitzpatrick and K. A. Scheidt, Adv. Synth. Catal., 2021, DOI: 10.1002/adsc.202101354; (c) B. Zhang, J. Qi, Y. Liu, Z. Li and J. Wang, Org. Lett. 2021, DOI: 10.1021/acs.orglett.1c03941.

19 (a) C. Lei, C. Lin, S. Zhang, X. Zhang, J. Zhang, L. Xing, Y. Guo, J. Feng, J. Gao, and D. Du, ACS Catal., 2021, 11, 13363-13373; (b) Y. Cai, J. Chen and Y. Huang, Org. Lett., 2021, 23, 9251-9255; (c) L. Wang, R. Ma, J. Sun, G. Zheng, Q. Zhang, ChemRxiv. 2021, DOI: 10.33774/chemrxiv-2021-5c17. (preprint).

20 (a) J. Guin, S. D. Sarkar, S. Grimme and A. Studer, Angew. Chem. Int Ed., 2008, 47, 8727-8730; (b) J. Zhao, C. Mück-Lichtenfeld and A Studer, Adv. Synth. Catal., 2013, 355, 1098-1106; pioneer work for employing aroyl fluorides as ketyl-type radical precursors see: (c) Q.Y. Meng, L. Lezius and A. Studer, Nat. Commun., 2021, 12, 2068; (d) Q.-Y. Meng, N. Döben and A. Studer, Angew. Chem. Int. Ed., 2020, 59, 19956-19960; (e) K. Liu and A. Studer, J. Am. Chem. Soc., 2021, 143, 4903-4909; (f) Z. Zuo, C. G. Daniliuc and A. Studer, Angew. Chem. Int. Ed., 2021, 60, 25252-25257.

21 (a) A. Mavroskoufis, M. Jakob and M. N. Hopkinson, ChemPhotoChem., 2020, 4, 5147-5153; (b) J. Liu, X.-N. Xing, J.-H. Huang, L.-Q. Lu and W.-J. Xiao, Chem. Sci., 2020, 11, 10605-10613.

22 F. Penteado, E. F. Lopes, D. Alves, G. Perin, R. G. Jacob, E. J. Lenardao, Chem. Rev., 2019, 119, 7113-7278.
23 (a) H. Zhang, W. Pu, T. Xiong, Y. Li, X. Zhou, K. Sun, Q. Liu and Q Zhang, Angew. Chem. Int. Ed., 2013, 52, 2529-2533; (b) H. Zhang, Y. Song, J. Zhao, J. Zhang and Q. Zhang, Angew. Chem. Int. Ed., 2014, 53, 11079-11083; (c) G. Zhang, T. Xiong, Z. Wang, G. Xu, X. Wang and Q. Zhang, Angew. Chem. Int. Ed., 2015, 54, 12649-12653; (d) G. Zheng, Y. Li, J. Han, T. Xiong and Q. Zhang, Nat. Commun., 2015, 6, 7011; (e) J. Sun, G. Zheng, T. Xiong, Q. Zhang, J. Zhao, Y. Li and Q. Zhang. ACS Catal., 2016, 6, 3674-3678; (f) T. Qin, G. Lv, Q. Meng, G. Zhang, T. Xiong and Q. Zhang, Angew. Chem. Int. Ed., 2021, 60, 25949-25957. 